\title{
PENINGKATAN KOMPETENSI KARYAWAN DAN SAFETY CULTURE MELALUI LEARNING MANAGEMENT SYSTEM "SINTESIS+" SEBAGAI KONTROL OPERASIONAL
}

\author{
Chandra Singgih Pitoyo ${ }^{1 *}$, Yuristian ${ }^{2}$, Cahyo Andrianto ${ }^{3}$, Riza Rahmah Angelia ${ }^{4}$ \\ 1 Learning Management Specialist, HSE Certification and Training Dept. PT Berau Coal, Berau, Kalimantan Timur \\ 2 HSE Training Superintendent, HSE Certification and Training Dept. PT Berau Coal, Berau, Kalimantan Timur \\ ${ }^{3}$ HSE Certification and Training Manager, HSE Certification \& Training Dept. PT Berau Coal, Berau, Kalimantan Timur \\ ${ }^{4}$ Process Analyst and Project Implementation Mining Technology PT Berau Coal, Berau, Kalimantan Timur
}

Artikel masuk :September 2019, Artikel diterima : Oktober 2019, Atikel terbit : November 2019

\section{ABSTRAK}

\begin{tabular}{|l|}
\hline \\
Kata kunci: \\
keselamatan, operasional, \\
pelatihan, teknologi, kompetensi \\
Keywords: \\
safety, operational, training, \\
technology, competency \\
\hline
\end{tabular}

Dengan luas konsesi sebesar 118.400 hektar dan memperkerjakan hingga lebih dari 21.694 karyawan dan mitra kerja, pengelolaan operasional dan keselamatan, kesehatan kerja, dan lingkungan (K3L) adalah hal yang harus diperhatikan. Tantangan yang harus dihadapi PT Berau Coal adalah lokasi yang tersebar di 4 (empat) wilayah operasional terpisah: Lati, Binungan, Sambarata, dan Marine. Selain itu, karyawan juga tidak memiliki banyak waktu untuk mengakses informasi, karena sebagian besar waktunya dihabiskan untuk bekerja dengan minimal waktu kerja 8 (delapan) jam perhari. Dengan latar belakang berbagai tingkat pendidikan, mulai dari SD hingga perguruan tinggi, juga menjadi tantangan tersendiri. Disamping itu, berdasarkan data, mayoritas karyawan PT Berau Coal dan mitra kerja berada pada rentang umur 24-40 tahun yang dapat dikategorikan sebagai generasi melek teknologi.

PT Berau Coal telah membangun sebuah platform pembelajaran bernama SINTESIS+ (Sistem Informasi Pelatihan dan Edukasi yang Sinergis) dan SID (Single Identity System). SINTESIS+ dan SID memiliki tujuan, antara lain (1) sebagai platform pembelajaran dan informasi terkait dengan operasional dan K3L, (2) meningkatkan kapasitas dan membangun kompetensi karyawan terkait operasional dan $\mathrm{K} 3 \mathrm{~L}$, terutama peran pengawas sebagai posisi kunci dalam program pengawasan keselamatan, (3) meningkatkan kontrol operasional terhadap kompetensi karyawan yang terkait dengan ijin masuk, ijin kerja, lisensi, serta spesialisasi, serta (4) mengintervensi perilaku untuk mewujudkan safety culture di karyawan internal dan mitra kerja.

Fitur dan konten yang dimiliki SINTESIS+ saat ini adalah online learning dengan konten pembelajaran multimedia, online testing dengan hasil yang real time, sertifikat yang otomatis muncul setelah pengguna lulus dalam online testing, webinar, berita insiden dan operasional pertambangan, repositori untuk portofolio kerja, sistem registrasi event dan pelatihan, terintegrasi dengan SID terkait perekaman data dan kontrol kompetensi karyawan dari segi operasional, baik itu ijin kerja, ijin masuk, lisensi, dan spesialisasi, serta proses yang dapat meningkatkan awareness terhadap K3L secara kontinyu.

Sejak peluncurannya, SINTESIS+ telah diakses oleh lebih dari 7867 karyawan, menguj pengetahuan untuk lebih dari 1024 ujian, menyelenggarakan webinar yang diikuti oleh 330 karyawan, serta menjalankan proses yang lebih efektif dan efisien, mulai dari pendaftaran hingga evaluasi. Dampak dari segi operasional atas integrasinya dengan sistem SID adalah meningkatnya compliance level terhadap pemenuhan kompetensi karyawan menjadi sebesar $98 \%$ dan proses pemantauan menjadi lebih efisien. Dengan peningkatan tersebut, selain kompetensi karyawan yang meningkat, kontrol terhadap operasional juga menjadi semakin baik, kesadaran terhadap K3L meningkat, dan dengan harapan tingkat insiden dapat menurun. Kedepannya, untuk meningkatkan akses dan safety culture, PT Berau Coal saat ini sedang mengembangkan platform aplikasi berbasis mobile untuk SINTESIS+. 


\section{ABSTRACT}

With 118.400 hectare of concession area and employed people for more than 21.694 employees within company and from business partners, Berau Coal needs to put more concern in managing operational and health, safety and environment (SHE). The challenges that need to be faced are location that scattered into 4 operational areas, limited time for employess to access information because most of time exploitated for working, various educational background, and technology literacy.

Berau Coal has been developed a learning platform, named SINTESIS+ and SID. The aims in development of those platforms are; (1) as a operational and HSE-themed learning platform, (2) to increase capacity and to build HSE and operational competencies, (3) to increase operational control for competencies related to entry permit, work permit, license, and specialization, and (4) to intervene employees' behaviour to build safety culture.

Features and contents that has been embedded in SINTESIS+ are online learning with multimedia materials, online testing with real time result, webinar, incident and mining operational news, repositories for employees' portfolio, event and training registration, integrated with SID to record employees' historical competency-related data, and sustainable process to increase HSE awareness.

Since its launching, SINTESIS+ has been accessed by 7867 employees, tested for 1024 exams, conducted webinar that participated by 330 employees, and run more effective and efficient processes. Impacts from integration process with SID are the increase of compliance level for competencies to $98 \%$ and the increase of process control efficiency. With those increments, beside the employees' compency and HSE awareness is increased, hoped to lower incident rate. In the future, to improve access to the platform, Berau Coal is willing to develop mobile apps for SINTESIS+ 


\section{PENDAHULUAN}

\section{Latar Belakang}

PT Berau Coal adalah sebuah perusahaan pertambangan yang diberi ijin perjanjian karya pengusaha pertambangan batubara (PKP2B) untuk beroperasi pada wilayah area operasional sebesar 118.400 hektar. Dengan luas besaran tersebut, menurut sistem single-identity per-Agustus 2019, Berau Coal mempekerjakan setidaknya 21.694 karyawan. Seluruh karyawan tersebut tergabung dalam internal perusahaan grup dan mitra kerja dengan total 186 perusahaan mitra.

Seluruh karyawan PT Berau Coal dan mitra kerja terbagi untuk bekerja di 6 area terpisah, antara lain Binungan, Lati, Sambarata, Marine, Eksplorasi, dan area Head Office, dengan jam kerja minimal 8 jam dan maksimal 12 jam untuk setiap harinya. Dengan proporsi waktu kerja yang begitu besar, serta ditambah dengan waktu untuk transportasi dan beristirahat, menyebabkan waktu yang digunakan karyawan untuk mengembangkan diri, termasuk belajar dan mengikuti pelatihan akan menjadi sangat terbatas. Menurut data yang dihimpun melalui sistem single-identity, sebesar $77.14 \%$ dari seluruh karyawan lahir pada tahun 19801999. Menurut The Millenial Generation Research Review NCF (2012) dalam Badan Pusat Statistik (2018), penduduk yang lahir pada tahun 1980-1999 termasuk ke dalam generasi milenial. Menurut Badan Pusat Statistik (2018), generasi milenial tersebut sangat dekat dengan teknologi, dibuktikan dengan $91.62 \%$ dari milenial menggunakan telepon seluler, $29.57 \%$ menggunakan komputer, serta $56.42 \%$ mengakses internet.

Dari aspek keselamatan dan kesehatan kerja, menurut OHS Dept di PT Berau Coal (2019) dalam Safety Performance Review, 14\% insiden yang terjadi sepanjang tahun 2018 disebabkan oleh skill dan kompetensi. Dari fakta tersebut memberikan informasi bahwa perlunya penguatan program yang terkait peningkatan skill dan kompetensi karyawan. Oleh karena hal tersebut, manajemen Berau Coal membuat sebuah kerangka kerja untuk meningkatkan kinerja produksi dan keselamatan, yaitu diantaranya adalah penguatan aspek proses (peningkatan kualitas dan konsistensi), sumber daya manusia (peningkatan kompetensi), dan implementasi teknologi.

Dari aspek proses bisnis internal, HSE Training Section PT Berau Coal, menyediakan pelatihan K3L untuk seluruh karyawan internal dan mitra kerja, dengan membuat kelas pelatihan di Training Center Samburakat, serta kelas paralel yang dilaksanakan oleh mitra kerja yang ditunjuk. Beberapa pelatihan K3L yang dikelola HSE Training ini, seperti Kelompok Materi Pelatihan Dasar (KMPD) dan Kelompok Materi Keselamatan Operasional Pertambangan (KMKOP), adalah prasyarat untuk izin yang diterbitkan Berau Coal, yaitu izin masuk daerah operasi, lisensi izin mengemudi perusahaan, serta izin-izin kerja khusus. Pada tahun 2018, Berau Coal setidaknya mengelola pelatihan untuk 49.303 orang, terdiri atas 15.809 orang yang dikelola sendiri dan 33.494 orang yang dikelola oleh kelas paralel mitra kerja, belum termasuk pengelolaan izin kerja yang diterbitkan (HSE Training, 2019).

Seluruh proses bisnis tersebut, dikelola dan dikontrol secara manual dan tidak tersistem, sehingga apabila terjadi perubahan yang mempengaruhi proses, misalnya pergantian sumber daya manusia, dan kesalahan penginputan, akan membutuhkan upaya yang besar. Selain manual, antar proses bisnis yang saling terkait juga belum memiliki integrasi. Seperti misalnya hubungan antar proses bisnis pelatihan dan izin kerja, karena pemegang kendali terhadap dua proses tersebut berbeda, menghasilkan data yang berbeda pula, padahal seharusnya jumlah izin yang diterbitkan sama dengan jumlah karyawan yang diberikan pelatihan terkait izin kerja terkait.

Selain itu, data yang dimiliki oleh Berau Coal tersebut digunakan hanya sebagai fungsi kontrol terhadap operasional pelaksanaan pelatihan. Selain karena data dinilai tidak reliable karena proses input dan pengolahan yang masih dilakukan secara manual, data tersebut tidak memiliki banyak informasi untuk dapat digali insight-nya, sehingga dari sekian banyak data yang diperoleh dari seluruh proses bisnis, tidak ada insight yang dapat disarikan untuk dijadikan bahan pengambilan keputusan. Oleh karena itu, Berau Coal menyadari perlunya sebuah transformasi teknologi untuk menjawab permasalahan-permasalahan tersebut.

Dari latar belakang dan seluruh permasalahan tersebut, Berau Coal membutuhkan sebuah solusi dengan tujuan (1) sebagai platform pembelajaran dan informasi terkait dengan operasional dan K3L, (2) meningkatkan kapasitas dan membangun kompetensi karyawan terkait operasional dan $\mathrm{K} 3 \mathrm{~L}$, terutama peran pengawas sebagai posisi kunci dalam program pengawasan keselamatan, (3) meningkatkan kontrol operasional terhadap kompetensi karyawan yang terkait dengan ijin masuk, ijin kerja, lisensi, serta spesialisasi, serta (4) mengintervensi perilaku untuk mewujudkan safety culture di karyawan internal dan mitra kerja.

\section{Rumusan Masalah}

Berdasarkan latar belakang yang telah diidentifikasi, rumusan permasalahan dalam penelitian ini adalah sebagai berikut:

1. Bagaimana cara menyampaikan pengetahuan K3L dan operasional secara mudah, informatif, dan real time kepada seluruh karyawan? 
2. Bagaimana cara meningkatkan kapasitas dan kompetensi dan kaitannya dengan kontrol operasional untuk meningkatkan safety culture?

Tujuan

Penelitian ini memiliki tujuan dalam rangka menjawab rumusan masalah yang telah dirumuskan, antara lain:

1. Merancang platform learning management system untuk menyampaikan pengetahuan terkait $\mathrm{K} 3 \mathrm{~L}$ dan operasional

2. Merancang proses integrasi dengan sistem SID untuk mengendalikan kompetensi karyawan untuk meningkatkan safety culture

\section{Pendekatan Pemecahan Masalah}

Penelitian ini memiliki kerangka pendekatan pemecahan masalah sebagai berikut:

1. Identifikasi dan perumusan masalah. Perumusan masalah dilakukan dengan beberapa metode, antara lain mengidentifikasi keinginan manajemen, mengindentifikasi harapan terhadap stakeholder terkait, serta melakukan analisis proses bisnis.

2. Perumusan alternatif solusi dan pemilihan solusi terbaik. Perumusan alternatif solusi dilakukan dengan identifikasi best practice yang dilakukan di perusahaan pertambangan lain, melakukan benchmark ke industri lain, serta mencari teknologi yang tersedia untuk membantu memecahkan masalah. Setelah semua alternatif solusi didapatkan, selanjutnya adalah memilih solusi terbaik dengan pertimbangan tertentu, seperti biaya yang dikeluarkan, waktu yang digunakan, fitur dan kemampuan sistem, serta feasibilitas penerapan.

3. Implementasi solusi. Dari solusi yang telah dipilih, kemudian diimplementasikan dalam perusahaan.

4. Evaluasi dan perancangan rencana perbaikan. Dari solusi yang telah dirancang dan diimplementasikan, langkah selanjutnya adalah menilai apakah solusi yang dipilih, dirancang, dan diimplementasikan telah dapat menyelesaikan masalah yang teridentifikasi. Dari hal yang dianggap belum dapat terpecahkan, dilakukan perancangan rencana perbaikan agar permasalahan yang dihadapi dapat diselesaikan dengan sepenuhnya.

\section{METODE}

Kerangka metodologi yang digunakan pada penelitian ini menggunakan kerangka seperti yang tergambar dalam Error! Reference source not found. Secara garis besar, metodologi yang digunakan mengacu pada software development life cycle dengan metode scrum atau agile yang iteratif.

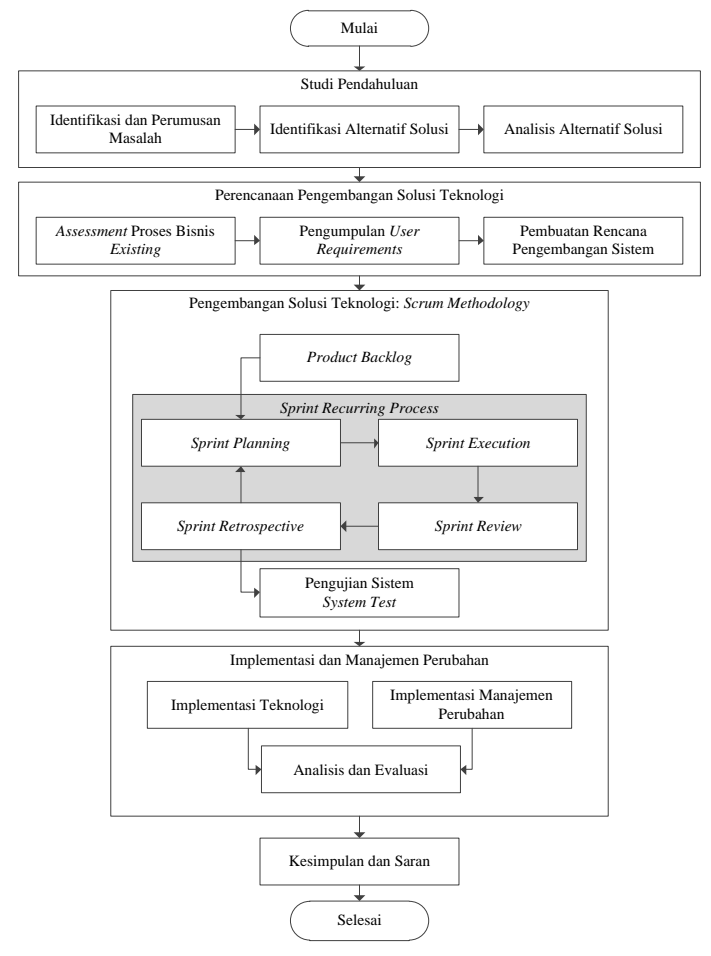

Gambar 1 Metodologi penelitian

Untuk lebih jelasnya, tahapan kerangka metodologi pada penelitian ini dijelaskan di bawah ini.

1. Studi Pendahuluan, yaitu tahap untuk mendefinisikan permasalahan yang sedang dihadapi dan dilakukan pemecahannya supaya memberikan dampak positif bagi stakeholder terkait.

2. Perencanaan Pengembangan Solusi Teknologi, yaitu tahapan untuk merencanakan pemecahan masalah yang telah didefinisikan menjadi rincian aktivitas yang dapat diimplementasikan.

3. Pengembangan Solusi Teknologi: Scrum Technology, yaitu tahapan pengembangan dan pembangunan solusi dengan basis teknologi, serta metode best practice implementasi teknologi.

4. Implementasi dan Manajemen Perubahan, yaitu tahapan penerapan solusi pada kegiatan operasional sehari-hari.

5. Kesimpulan dan Saran, yaitu tahapan penarikan kesimpulan dan saran untuk penelitian selanjutnya.

\section{HASIL DAN PEMBAHASAN}

\section{Studi Pendahuluan}

SINTESIS+ adalah platform LMS yang dibangun sebagai sarana informasi pengetahuan K3L dan operasional. Dalam perancangannya memiliki dua 
alternatif solusi, yaitu aplikasi in-house atau kustomisasi dan aplikasi open-source atau bebas lisensi menggunakan Modular Object-Oriented Dynamic Learning Environment (Moodle) yang mampu mengakomodir kebutuhan user sebagai berikut:

1. Penyimpanan data peserta

2. Laporan histori aktivitas peserta

3. Modul ujian online

4. Klasifikasi silabus kursus online
5. Penjadwalan pelatihan online

6. Report hasil ujian dalam bentuk dashboard

7. Sistem yang terintegrasi dengan data karyawan

Setelah dilakukan penyesuaian kebutuhan dan alternatif solusi, maka dibutuhkan identifikasi perbandingan antara keduanya. Didapatkan masingmasing kekurangan dan kelebihannya adalah seperti pada tabel 1.

Tabel 1. Perbandingan Alternatif Solusi

\begin{tabular}{|c|c|c|}
\hline Produk Aplikasi & Apps In-house & Moodle Open Source \\
\hline Kelebihan & $\begin{array}{l}\text { Mudah kustomisasi hingga } \\
\text { kebutuhan user yang } \\
\text { advanced }\end{array}$ & $\begin{array}{l}\text { Tidak bergantung kepada developer karena mudah } \\
\text { dikonfigurasi, fleksibel dan memiliki banyak fitur, } \\
\text { dibuktikan dari banyak plug-in yang tersedia } \\
\text { Terpercaya karena sudah terimplementasi di } \\
\text { berbagai lini instansi, dibuktikan dari support Global } \\
\text { Community }\end{array}$ \\
\hline Kekurangan & $\begin{array}{l}\text { Ketergantungan pada } \\
\text { developer untuk konfigurasi } \\
\text { dan pengembangan fitur } \\
\text { Belum pernah ada yang } \\
\text { mengimplementasikan } \\
\text { karena aplikasi khusus } \\
\text { dibuat sesuai kebutuhan } \\
\text { masing-masing lini }\end{array}$ & $\begin{array}{l}\text { Sulit kustomisasi karena keterbatasan fitur aplikasi } \\
\text { open-source }\end{array}$ \\
\hline
\end{tabular}

Hasil analisa dari solusi yang ada, Moodle dinyatakan sebagai platform pembelajaran yang layak diimplementasikan di PT Berau Coal. Selain dilihat dari keunggulan Tabel 1, Moodle juga memiliki waktu pengembangan yang cepat serta jaringan dan keamanannya mudah dikonfigurasi. Berdasarkan riset dari University of Gdansk di Polandia, keuntungan menggunakan Moodle terbukti dari survey yang diisi mahasiswa setelah mengalami perubahan proses pembelajaran, seperti: $85.7 \%$ mahasiswa menyetujui akses material belajar menjadi lebih mudah, $48.3 \%$ mengaku lebih efisien dan cepat dalam komunikasi dengan instruktur, $47.6 \%$ setuju mengalami peningkatan selama kelas setelah mengakses materi, $45.6 \%$ setuju persiapan belajar sebelum ujian menjadi terbantu. Dari hasil survey disimpulkan Moodle sangat dibutuhkan dalam kemudahan akses karena tampilannya yang sederhana dan mudah, namun offline atau tatap muka dengan instruktur masih dibutuhkan untuk memaksimalkan hasil proses belajar mengajar.

\section{Perencanaan Pengembangan Solusi Teknologi}

Dilihat dari kemampuan sistem serta fitur yang ditawarkan oleh platform SINTESIS+, ada beberapa proses yang berubah dari proses ketika belum diterapkannya platform ini. Berikut adalah proses bisnis yang berubah dan dapat digantikan dengan proses yang lebih efektif dan efisien dengan bantuan platform SINTESIS+

Tabel 2. Aspek Perubahan Prodrd Bisnis

\begin{tabular}{|c|c|c|}
\hline Aspek & Kondisi Existing & Kondisi Desired \\
\hline Pendaftaran & $\begin{array}{l}\text { Karyawan mendaftar melalui surel, } \\
\text { dengan melampirkan berkas } \\
\text { persyaratan. Admin melakukan } \\
\text { pendataan dan alokasi peserta ke } \\
\text { pelatihan yang tersedia. }\end{array}$ & $\begin{array}{l}\text { Dengan fitur event management, pendaftar } \\
\text { dapat memilih tanggal sesuai } \\
\text { keinginannya. Admin hanya melakukan } \\
\text { proses persetujuan. }\end{array}$ \\
\hline Proses Pelatihan & $\begin{array}{l}\text { Untuk refresh pelatihan tahunan, } \\
\text { karyawan mengikuti kelas tatap } \\
\text { muka. }\end{array}$ & $\begin{array}{l}\text { Proses pembelajaran dilakukan secara } \\
\text { mandiri (self learning). }\end{array}$ \\
\hline
\end{tabular}




\begin{tabular}{|c|c|c|}
\hline Evaluasi Pelatihan & $\begin{array}{l}\text { Karyawan melakukan paper-based } \\
\text { test. Hasil dikoreksi dan } \\
\text { direkapitulasi per peserta secara } \\
\text { manual. }\end{array}$ & $\begin{array}{l}\text { Karyawan melakukan online test } \\
\text { menggunakan computer-based-test. Hasil } \\
\text { langsung dilihat secara real time dan } \\
\text { terekap dalam basis data. }\end{array}$ \\
\hline Pasca-pelatihan & 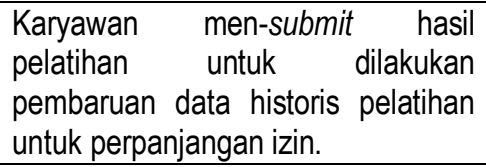 & $\begin{array}{l}\text { Hasil pelatihan langsung terkirim dan } \\
\text { melakukan pembaruan data historis secara } \\
\text { otomatis ke dalam sistem single identity. }\end{array}$ \\
\hline Pelaporan & $\begin{array}{l}\text { Data direkapitulasi dan diolah secara } \\
\text { manual dengan tabulasi. }\end{array}$ & $\begin{array}{l}\text { Dashboard secara otomatis diperbarui } \\
\text { sehingga dapat menghasilkan insight untuk } \\
\text { mendukung pengambilan keputusan }\end{array}$ \\
\hline Izin Operasional & $\begin{array}{l}\text { Pemantauan dan pengendalian izin } \\
\text { yang terbit secara manual apabila } \\
\text { kompetensi telah kadaluarsa. }\end{array}$ & $\begin{array}{l}\text { Sistem akan memberikan notifikasi apabila } \\
\text { kompetensi telah kadaluarsa dan akan } \\
\text { terjadi automatis block izin kerja apabila } \\
\text { kompetensi telah kadaluarsa. }\end{array}$ \\
\hline
\end{tabular}

Selain ada proses-proses yang berubah, adanya platform SINTESIS+ juga membantu proses yang saat ini dijalankan secara manual menjadi terotomasi dengan sistem. Cara SINTESIS+ membantu meningkatkan efektivitas dan efisiensi proses adalah dengan menyediakan fitur-fitur yang tersedia. Adapun kaitannya antara fitur dengan fitur yang disediakan SINTESIS+ dengan proses yang saat ini dijalankan adalah sebagai berikut.

Tabel 1 Keterkaitan fitur dan proses bisnis

\begin{tabular}{ll}
\hline \multicolumn{1}{c}{ Fitur } & \multicolumn{1}{c}{ Proses Terkait } \\
\hline User Management & $\begin{array}{l}\text { Proses Perekaman Data } \\
\text { Historis Pelatihan }\end{array}$ \\
\hline Dashboard Activity & $\begin{array}{l}\text { Proses Monitoring Kompetensi } \\
\text { Personal Karyawan }\end{array}$ \\
\hline Test Module & $\begin{array}{l}\text { Proses Ujian / Evaluasi } \\
\text { Pelatihan }\end{array}$ \\
\hline Course Module & Proses Pelatihan \\
\hline Scheduling & Proses Penjadwalan Pelatihan \\
\hline Reporting & $\begin{array}{l}\text { Proses Pelaporan Aktivitas } \\
\text { Pelatihan }\end{array}$ \\
\hline System Integration & $\begin{array}{l}\text { Proses Pengajuan Izin } \\
\text { Operasional }\end{array}$ \\
\hline
\end{tabular}

Proses pengembangan sistem ini menggunakan metode scrum yang terdiri atas sprint-sprint pendek. Penyusunan fitur-fitur apa saja yang dibangun terlebih dahulu dalam SINTESIS+ menyesuaikan dengan 2 (dua) hal, yaitu prioritas fitur dan sumber daya yang tersedia (alokasi waktu dan sumber daya manusia yang terlibat). Berikut adalah timeline pengembangan platform SINTESIS+ yang telah disusun dengan mempertimbangkan prioritas fitur dan alokasi sumber daya.
Tabel 2 Timeline sprint pengembangan platform SINTESIS+

\begin{tabular}{cl}
\hline Sprint & Elemen Pengembangan \\
\hline Sprint 1 & Halaman utama \\
& Kebutuhan sistem website \\
& $\begin{array}{l}\text { Upload download materi } \\
\text { pembelajaran }\end{array}$ \\
\hline Sprint 2 & Biodata karyawan \\
& Online test \\
& Hasil online test \\
& Bank soal \\
\hline Sprint 3 & Konfigurasi pelatihan wajib \\
& Otentikasi test \\
& Integrasi single identity \\
& Event management \\
& Dashboard \\
& Pengolahan data pelaporan \\
& Notifikasi jadwal event \\
\hline Sprint 4 & Monitoring dan tracking \\
& Konfigurasi tampilan \\
& Fitur pencarian dan unduhan \\
\hline Sprint 5 & Reminder pertahun \\
\hline
\end{tabular}

1. Pengembangan Solusi Teknologi: Scrum Methodology

Sprint adalah kumpulan product backlog yang diurutkan berdasarkan prioritas kebutuhan user dan effort pengerjaan developer. Pada studi kasus SINTESIS+ sebanyak 19 backlog akan dikelompokkan menjadi 6 sprint yang masing-masingnya memiliki periodik pengerjaan waktu setiap 2 minggu. Berdasarkan Buku "Agile Project Management for Dummies" ada beberapa aktivitas Scrum yang 
dikerjakan berulang, diantaranya sprint planning, execution, review dan retrospective.

a. Sprint Planning: Pendefinisian kategori sprint yang akan dilakukan oleh customer/stake holder sebagai end user, product owner, scrum master dan scrum team. Masing-masing sprint dirancang waktu pengerjaannya, proses saat ini dibandingkan dengan pengerjaan aktual, team scrum yang mengerjakan dan goals fitur masing-masing sprint.

b. Sprint Execution: Eksekusi backlog berdasarkan urutan sprint yang sudah memiliki timeline. Tim Scrum akan melakukan eksekusi sesuai kemampuan yang telah dipetakan oleh Scrum Master.

c. Sprint Review: Review hasil pengerjaan sprint execution, penentuan review meeting untuk kasus SINTESIS+ sepakat dilakukan 2 minggu sekali di hari Kamis. Product owner akan menentukan apakah hasil sprint sesuai dengan kebutuhan, perlukah diperbaiki dan perlukah sprint berikutnya dikerjakan sesuai rencana.

d. Sprint Retrospective: Disinilah tim scrum diperbolehkan untuk memperbaiki hasil review sprint yang tidak sesuai dengan kebutuhan user, maupun ketertinggalan pengerjaan di sprint sebelumnya. Kemudian, hasilnya akan disampaikan bersamaan dengan review meeting sprint berikutnya.

Manfaat dari iterasi atau aktivitas berulang di Scrum pada pengembangan adalah memungkinkan user/stakeholder untuk melakukan koreksi di setiap aktivitas project agar seluruh tim mendapatkan pemahaman yang lebih baik. Hubungan antara user dan tim scrum akan lebih sering berinteraksi melalui review meeting, sehingga meminimalisir missed perception, bottle neck dengan permasalahan yang tidak terpecahkan

Berikut adalah role dalam metodologi scrum:

a. Customer/Stakeholder adalah tim HSE Certification \& Training (HSE-CT) Dept yang memberikan list kebutuhan kepada Product Owner.

b. Product Owner adalah Project Manager dari tim HSE CT Dept yang memahami proses bisnis dan tim Mining Technology (Minetech) Dept yang memahami flow proses teknologi memberikan feedback berupa business value agar mudah dipahami antara user dan tim Scrum.

c. Product Owner melakukan sortir dari minimum value product (MVP) menjadi aktivitas prioritas berdasarkan daftar kebutuhan.

d. Scrum Master adalah Project Manager dari tim Minetech Dept yang memahami proses System Development Life Cycle (SDLC) metodologi Scrum dan Project Manager dari tim Developer untuk memetakan pengerjaan sesuai kemampuan tim developer

e. Scrum Master melakukan cek backlog dan mendefinisikan Acceptance Criteria

f. Scrum Master melakukan cek aktivitas kepada Scrum Team

g. Scrum Team menyimulasikan product increment kepada Product Owner dalam sprint review

h. Scrum Team menyerahkan progress project untuk direview ke Customer

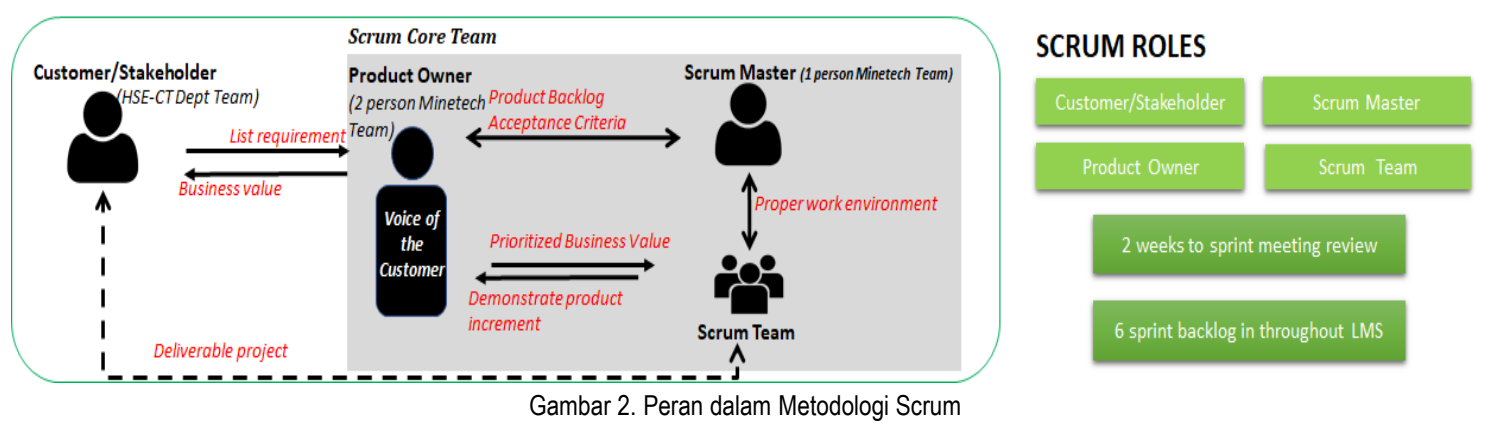

Dari penggunaan metodologi Scrum, seluruh pengerjaan pengembangan dinyatakan solved dan berhasil diterima setelah dilakukan pengujian keseluruhan use-case sistem. Selain itu, waktu pengerjaan lebih terorganisir dan terkontrol karena feedback antar pihak yang saling berkesinambungan dan intens.

2. Implementasi dan Manajemen Perubahan
Setelah platform dibangun dengan bantuan pihak ketiga. Langkah yang selanjutnya dilakukan adalah implementasi platform ke dalam kegiatan operasional sehari-hari. Berikut adalah hasil dari implementasi platform SINTESIS+ setelah 8 (delapan) bulan berjalan dengan data per-Agustus 2019.

Tabel 3 Hasil implementasi SINTESIS+ 


\begin{tabular}{lc}
\hline Login pengguna & 19005 pengguna \\
Login unik pengguna & 3619 pengguna \\
$\begin{array}{l}\text { Konten digital } \\
\text { multimedia }\end{array}$ & 120 modul \\
Jenis konten tersedia & 8 jenis konten \\
Pelaksanaan webinar & 9 kali \\
Pelaksanaan ujian & 3244 pengguna ujian \\
\hline
\end{tabular}

Penerapan SINTESIS+ dalam kegiatan operasional juga terkait dengan integrasi sistem yang telah ada. Integrasi antara SINTESIS+ dengan sistem single identity menghasilkan sebuah proses pemantauan kompetensi terhadap izin operasional yang diterbitkan. Dari hasil perhitungan terkait dengan izin operasional yang berupa izin masuk daerah operasional dan izin kerja khusus, didapatkan bahwa $98 \%$ dari seluruh karyawan internal dan mitra kerja dinyatakan comply terhadap pemenuhan persyaratan kompetensi yang terkait.

Paralel dengan implementasi platform dalam kegiatan operasional, Berau Coal juga melakukan implementasi manajemen perubahan. Perubahan terkait dengan aktivitas, prosedur, sumber daya, tugas dan tanggung jawab dikelola agar implementasi teknologi dapat berjalan dengan baik, serta diperoleh dampak yang tepat sasaran. Adapun manajemen perubahan yang telah dilakukan antara lain adalah sebagai berikut.

1. Rekayasa proses bisnis, diterapkan untuk mengubah proses bisnis lama (sebelum diterapkannya platform SINTESIS+) menjadi proses bisnis yang baru terhadap stakeholder yang terkait

2. Implementasi test center, diterapkan untuk menyediakan fasilitas dan sarana karyawan untuk melakukan ujian dan pembelajaran

3. Sosialisasi, diterapkan untuk menyediakan informasi terkait sistem yang telah dibangun untuk membantu dan memudahkan kegiatan operasional

4. Migrasi menyeluruh, diterapkan untuk menutup channel dimana cara-cara lama (tanpa menggunakan teknologi) tidak dapat dilakukan lagi

Dari penelitian ini, implementasi SINTESIS+ dalam rangka meningkatkan kompetensi dan safety culture sebagai kendali operasional adalah sebagai berikut.

Kelebihan:

1. SINTESIS+ menggunakan basis Moodle, yaitu sebuah platform learning management system yang telah banyak digunakan oleh berbagai instansi di berbagai industri, sehingga fitur dan alur kerja yang dimiliki merupakan best practice pembelajaran

2. Implementasi teknologi SINTESIS+ telah dapat mengakomodasikan kebutuhan pengguna, serta terintegrasi dan relevan dengan sistem single identity

3. Implementasi teknologi SINTESIS+ juga menyertakan manajemen perubahan, sehingga proses utilisasinya dalam membantu meningkatkan kompetensi dan safety culture dapat berjalan dengan baik

Kekurangan:

1. SINTESIS+ adalah platform yang berbasis web, sehingga untuk menggunakannya diperlukan perangkat yang sesuai, yang menyebabkan aksesibilitasnya terbatas

2. Proses manajemen perubahan harus lebih intensif diimplementasikan untuk dapat menjaring seluruh karyawan tanpa terkecuali.

Adapun rencana pengembangan ke depan adalah pengembangan platform SINTESIS+ ke dalam bentuk mobile application sehingga dapat diakses kapanpun dan dimanapun. Selain itu, perlu dibuat programprogram untuk lebih mengenalkan SINTESIS+ kepada seluruh karyawan internal dan mitra kerja.

\section{KESIMPULAN DAN SARAN}

Adapun kesimpulan dari penelitian ini adalah sebagai berikut:

1. SINTESIS+ mampu dijadikan solusi teknologi sebagai sarana penyampaian informasi dan pembelajaran terkait dengan K3L dan operasional terbukti dari pencapaiannya pada hasil implementasi SINTESIS+ dan hingga saat ini telah diimplementasikan di Berau Coal

2. SINTESIS+ mampu mendukung control operasional melalui system pembelajaran yang terintegrasi dengan sistem single identity yang menjembatani antara kompetensi karyawan dengan izin operasional.

\section{UCAPAN TERIMA KASIH}

Ucapan terima kasih kami sampaikan kepada seluruh pihak yang telah berkontribusi dalam proyek SINTESIS+ ini. Terima kasih kepada seluruh karyawan PT Berau Coal yang telah berperan serta dalam penerapan SINTESIS+ terutama Project Sponsor yaitu Bapak Arief Wiedhartono selaku Operation and HSE Director, Bapak Feri Indrayana selaku Kepala Teknik Tambang. Kemudian, terima kasih juga kami ucapkan kepada Project Leader yaitu Bapak Febriwiadi Djali selaku System \& Compliance General Manager serta Bapak Arif Widya Susanto selaku Mining Technology Manager. Tidak lupa kami ucapkan kepada seluruh tim yang terlibat mulai dari HSE Certification \& Training team, Mining Technology team, System Development team, dan HSE Campaign team. 
DAFTAR PUSTAKA

HSE Training Dept. 2019. PT Berau Coal.

Lambda Solutions. n.d. The Complete User Guide To Moodle Chapter 1.

Layton, Mark C. 2012. Agile Project Management For Dummies.

- . n.d. The Function of the Scrum and Sprint within an Agile Project. Accessed 09 16, 2019. https://www.dummies.com/careers/projectmanagement/the-function-of-the-scrum-andsprint-within-an-agile-project/.

PT Berau Coal. 2018. "Safety Townhall." Jakarta.
Statistik, Badan Pusat. 2012. "The Millenial Generation Research Review NCF ." The Millenial Generation Research Review NCF . Badan Pusat Statistik.

Szadziewska, Arleta, and Jaroslaw Kujawski. 2017. "ADVANTAGES AND DISADVANTAGES OF THE BLENDED-LEARNING METHOD USED IN THE EDUCATIONAL PROCESS AT THE FACULTY OF MANAGEMENT AT THE UNIVERSITY OF GDANSK, IN THE OPINION OF UNDERGRADUATE STUDENTS." 10th annual International Conference of Education, Research and Innovation. Seville, Spain: Proceedings of ICERI2017 Conference. 3938-3946. 